\title{
Concept for the Intermountain Center for Mining Research and Development
}

Gerald L. May

June 2005

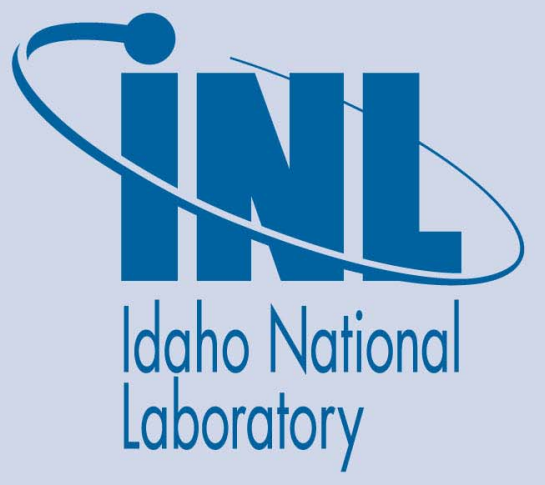

The INL is a U.S. Department of Energy National Laboratory operated by Battelle Energy Alliance 
INL/EXT-05-00469

\title{
Concept for the Intermountain Center for Mining Research and Development
}

\author{
Gerald L. May
}

June 2005

\begin{abstract}
Idaho National Laboratory
Idaho Falls, Idaho 83415
\end{abstract}

Prepared for the

U.S. Department of Energy

Office of Nuclear Energy

Under DOE Idaho Operations Office

Contract DE-AC07-05ID14517 


\section{CONTENTS}

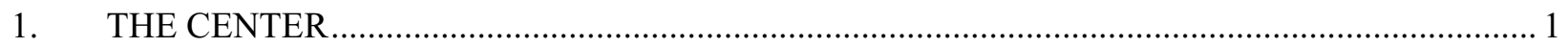

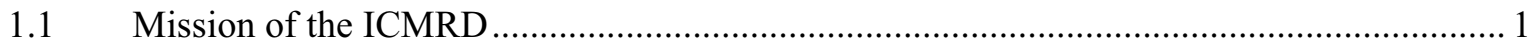

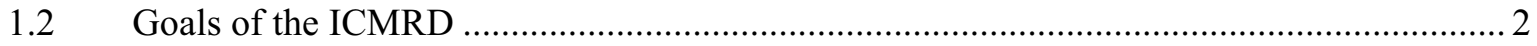

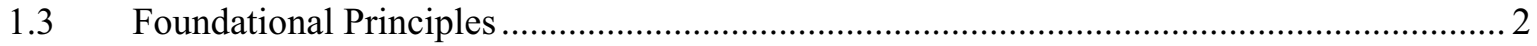

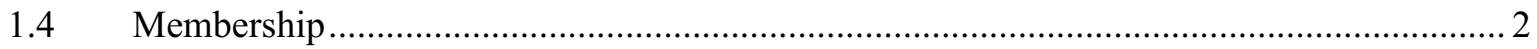

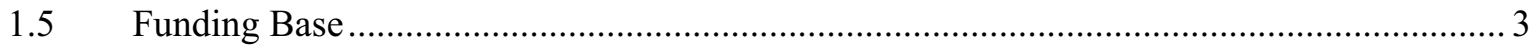

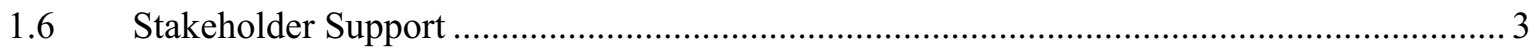

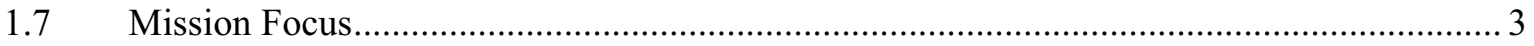

$1.8 \quad$ Key Management Activities ................................................................................... 3

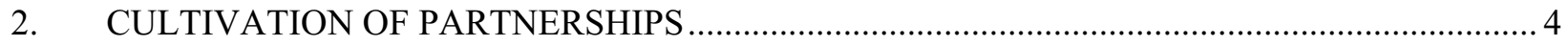

2.1 Maintaining Awareness of Mining and Mineral Policy Decisions..................................... 4

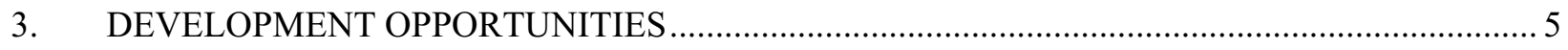

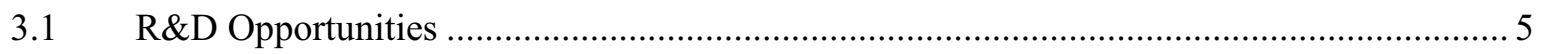

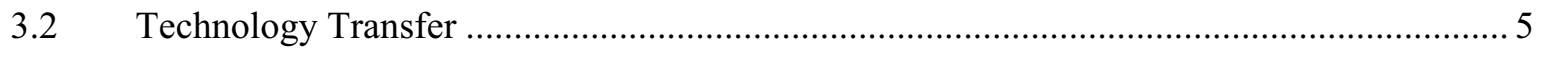

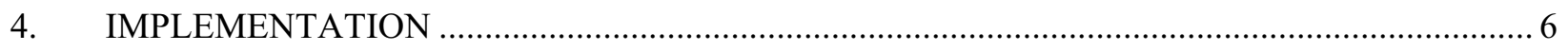

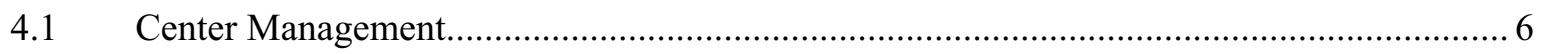

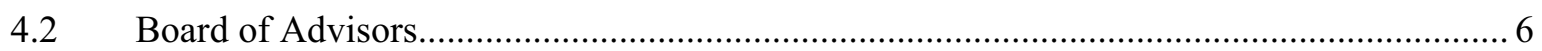

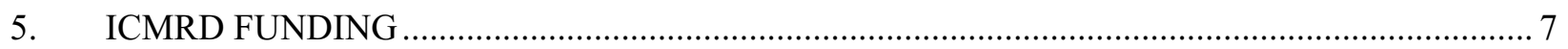

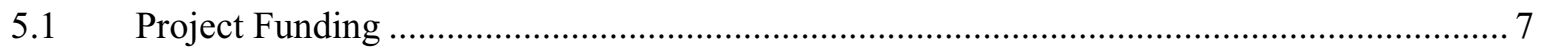




\title{
Concept for the Intermountain Center for Mining Research and Development Draft
}

\author{
INTRODUCTION: THE CENTER
}

The Intermountain Center for Mining Research and Development (ICMRD) was established with the Idaho National Laboratory (INL) as the cornerstone, and with regional universities, mining schools, and the Western mining industry as full members. In aggregate, the members provide the strong mining research and development capabilities and knowledge that are essential to the success of such a research center.

The ICMRD is an organization that identifies technical needs, partially funds, and provides project management for research projects. The ICMRD will primarily serve the nine Intermountain States, but will not restrict other regions, research organizations, or academic institutions from membership. The ICMRD's nine primary states are: Idaho, Montana, Wyoming, Utah, Colorado, Nevada, Arizona, Alaska, and New Mexico.

The business and project management functions of the ICMRD will be located at INL. Research projects may be performed by INL, one of the member research organizations, academic institutions, mining companies/suppliers, or preferably, by a partnership of several of these institutions. Teaming among members will be essential in providing quality $R \& D$.

The ICMRD will accomplish its research goals by creating partnerships between the research organizations, federal and state agencies, and the mining industry. The ICMRD will provide project management, technical and financial support, and technology transfer opportunities. The ICMRD, through its associated academic partners, will provide a base for development and testing of mining, metallurgical, and environmental technologies in the laboratory through pilot-scale environments. Through these partnerships, the ICMRD will provide a vehicle to achieve its objectives of developing innovative mining technologies, enhancing the capabilities of the regional mining schools and universities, and improving the global competitiveness of the U.S. mining industry.

\section{Mission of the ICMRD}

The ICMRD was established to encourage and facilitate mining-related research and technology transfer in the Intermountain States. In addition, the ICMRD will develop financial and working relationships with various organizations and agencies as needed to accomplish the ICMRD objectives.

The ICMRD will focus on R\&D to address major concerns confronting mining in the Intermountain region now and in the future, including:

- $\quad$ Minimizing and controlling wastes

- Improving separation and recovery processes aimed at recovering minerals and metals from lowgrade and complex ores

- $\quad$ Developing better sensors and control equipment for mining and processing operations.

- $\quad$ Developing innovative, environmentally acceptable mining, ore extraction, and material handling methods and technologies. 
The ICMRD will also provide guidance to researchers and industry, particularly regarding trends in science and technology that may shift program focus in the long term.

\section{Goals of the ICMRD}

The goals of the ICMRD are to:

- Create a mechanism to coordinate mining-related research in the Intermountain region

- Utilize and build competency in mining research at regional academic institutions and research laboratories

- Involve the mining industry (both producers and suppliers) in research and development work centering on projects with technical interest and economic value

- $\quad$ Enhance opportunities for transfer of existing technology, develop additional technology along industry-identified lines, and increase relevancy to industry.

\section{Foundational Principles}

In establishing the direction and approach to its mission, ICMRD personnel will adhere to certain foundational principles. These principles are integral to the philosophy and vision of the ICMRD and will serve as guidance to officials charged with drafting project agreements and personnel involved in day-today conduct of business. The following principles will be essential.

- The ICMRD will maintain the highest ethical and legal standards in the conduct of business and will require the same of all members and customers

- $\quad$ The ICMRD will undertake only those projects that clearly benefit its members and sponsors and meet the criteria set by the Board of Advisors

- A clear, fair, and timely mechanism to review and prioritize research proposals will be established and followed

- $\quad$ The ICMRD will focus its resources on the accomplishment of its core mission.

\section{Membership}

The ICMRD will consist of several levels of membership. Depending on the level, a membership fee may be required and will be determined by the Board of Advisors. The following types of organizations are expected to become members.

- $\quad$ Regional Colleges and Universities

- $\quad$ Mining Companies

- Industrial Manufacturers and Suppliers

- $\quad$ Other Research Laboratories

- Industry Organizations and Associations. 


\section{Funding Base}

Quality program management and fiscal responsibility are foremost to the ICMRD's objectives. The ICMRD's primary funding source will be a yearly appropriation from Congress through one or several of the governments departments or agencies. This funding will provide the ICMRD's overhead costs and provide a matching fund base for research. Industry matching funds on specific projects will be a second major source of funds. Relationships will be developed with other entities with common interests with the objective of securing additional resources for research that meets the goals of the ICMRD.

\section{Stakeholder Support}

It is essential that the ICMRD successfully meet needs of its stakeholders. This will be accomplished through:

- $\quad$ Strong, cost effective management

- $\quad$ Successful research results with real economic value or public benefit

- Active participation of stakeholders in roles such as:

- $\quad$ Board of Advisors members

- $\quad$ Technical committee members

- $\quad$ Project review board members

- Seminar attendance

- A mechanism to receive regular assessment from stakeholders on ICMRD effectiveness.

Initially, there will also be a focus on leveraging existing capabilities and research to demonstrate early successes on ICMRD projects.

\section{Mission Focus}

Active involvement by stakeholders through the Board of Advisors and technical committees, coupled with strong emphasis by the Center management team, will ensure that Center work remains strongly focused on the Center's goals.

\section{Key Management Activities}

During startup and early operation, resources must be targeted in four key areas:

- $\quad$ Membership development

- $\quad$ Processes for successful technology R\&D

- Communication of the success of the ICMRD to stakeholders

- Development of new funding sources. 


\section{CULTIVATION OF PARTNERSHIPS}

An essential goal of the ICMRD is to establish, encourage, and facilitate mining related research through partnerships or other working relationships. ICMRD management will endeavor to explore areas for possible partnership development, identify specific industrial targets for such relationships, develop proposals and agreement documents, establish the working basis/parameters for such partnerships, and develop guidelines for long-range maintenance of these partnerships. To focus the research efforts, the ICMRD will require that each research project be sponsored by an industrial partner(s) willing to pay a minimum of fifty percent of the project costs, if the remainder is funded through base federal ICMRD funding.

\section{Maintaining Awareness of Mining and Mineral Policy Decisions}

Policy concerning the minerals industries changes frequently, depending on the current Federal, State, and local government administration. The ICMRD will maintain awareness of policy decisions, environmental guidelines, and laws that may affect the focus of research and development projects. This information will be communicated to Center members through special publications and by inviting key speakers to Center meetings. 


\section{DEVELOPMENT OPPORTUNITIES}

Industry believes much is needed in the area of technology development to improve the viability of the U.S. mining industry. As an example, viability can be increased by increasing the lives of operating mines by economically recovering metals from materials once thought of as wastes. More and better technologies are needed as ore grades continue to drop, mineral complexities increase and regulatory pressures build. Most technologies developed for the mining industry are crosscutting with many other industries. These technologies include membranes for separations of metals, new instrumentation for measurement of process variables to improve process control, and computer modeling and imaging systems for exploration or process optimization. Opportunities for cooperative research or technology transfer with other industries may be explored through, for example, joint meetings with associations of the chemical or oil and gas industries.

\section{R\&D Opportunities}

In the coming century, there will be great pressure to increase efficiency in terms of labor cost, capital investment, energy cost, safety, and environmental sensitivity through technology. Social and environmental factors may have strong influence. As an example, to increase safety, greater use of remotely controlled and autonomous robotic equipment, progressing toward "intelligent" mining systems requiring minimal human intervention will be employed.

\section{Technology Transfer}

Projects receiving federal funds from the ICMRD must make all technologies developed as a result of this funding available to the industry as a whole. Access can be provided through several mechanisms, such as direct product sales, licensing intellectual property, or developing spin-off companies. However, special rights are often given to research partners, whereby they may receive royalty-free rights of use or may have exclusive access to the technology for a limited period of time. Under special arrangement, intellectual property may be protected for up to five years. If a sponsoring partner(s) wants exclusive rights to the technology, they will have the option of funding 100 percent of the program.

INL will make its Technology Transfer organization available to the ICMRD for support of the needed technology transfer activities. 


\section{IMPLEMENTATION}

The program implementation and management strategy will be developed later in conference with the Board of Advisors, and will focus on managing the center and the role of the Board of Advisors.

\section{Center Management}

A Center management team will manage the day-to-day activities of the Center. The team will be comprised of a full time Center/Program Manager, and as-needed program manager(s), administrative assistant and accounting help. The center management team will implement the mission and goals of the ICMRD, and through the guidance of the Board of Advisors, provide technology development insight to the Center members. Additional duties will include promoting the capabilities of the Center to regional

mining companies and reviewing requested proposals to make sure they meet the specific criteria of the scope of work. One of the team's primary responsibilities will be program management oversight to existing R\&D programs in order to ensure high quality work and on-time delivery.

\section{Board of Advisors}

The ICMRD will have a Board of Advisors to assist the ICMRD management team in setting proposal selection criteria and implementation policy for the ICMRD. Members of the board will be selected as follows: five (5) from the mining industry, two (2) from academia, and two (2) from service organizations or associations. The board will be selected on a staggered three-year appointment. Each selected board member is expected to be senior technical management within their respective institutions. They will provide the ICMRD with valuable insight into the technical and environmental needs of the mining industry. The Board will meet at least once per calendar year.

Duties of the Board of Advisors are:

- $\quad$ Promote the general welfare and competency of the ICMRD

- Develop the ICMRD operating criteria for the coming year for both project focus and project selection

- Work with the INL program manager to identify new customers for the ICMRD

- Assist in maintaining existing funding and securing additional funding sources for the ICMRD

- Interact with national and local mining associations for the benefit of ICMRD. 


\section{ICMRD FUNDING}

The principal funding source for the ICMRD will be a funding allocation from Congress through one of the governments departments or agencies. It will be proposed that this funding start at approximately $\$ 5 \mathrm{M}$ and be increased yearly to approximately $\$ 10 \mathrm{M}$. A small percentage of the congressional funding will be used for ICMRD overhead with the remaining being allocated to research projects.

Additional funding sources may be other federal departments or agencies, such as USDA, DOE, DOI, EPA or BLM, state governments, and mining associations. These funds may be provided in the form of project funding or grants, and be earmarked for special technology development, and may not require matching industrial funding.

The final source for funding will be the required matching funds for each project required from the ICMRD's industry partners. There may also be a required membership fee, to be determined by the Board of Advisors, from each member institution. The membership fee would be applied to offset program expenses.

\section{Project Funding}

Each project submitted and approved, meeting the acceptance criteria set by the ICMRD Board of Advisors, will receive up to fifty percent of its estimated project costs in funding from the ICMRD and the remainder from the customer or sponsor. Up to one-half $(1 / 2)$ of the funding from the project customer or sponsor may be an in-kind contribution. This will be determined on a project-by-project basis.

Projects will be managed through subcontracts. The duration of projects will be variable, depending upon the work requirements, and may extend over several years. Projects will be funded initially for one year with future funding dependent on satisfactory progress. A review board will review projects yearly. Payment will be made to the research institutions at least quarterly. Each research institution will be required to meet and maintain the standards of quality and ethics set by the ICMRD, and provide a quarterly written report to the ICMRD describing the efforts of the past quarter. 